\title{
Compressive Strength and Dimensional Stability of Palm Oil Empty Fruit Bunch Fibre Reinforced Foamed Concrete
}

\author{
Siong Kang Lim ${ }^{1 *}$, Hock Yong Tiong ${ }^{1}$ and Kai Siong Woon ${ }^{1}$ \\ ${ }^{1}$ Department of Civil Engineering, Lee Kong Chian Faculty of Engineering \& Science, Universiti \\ Tunku Abdul Rahman, Selangor, Malaysia
}

\begin{abstract}
Rapid drying shrinkage is an important factor in causing cracks of concrete. This research was aimed at studying the effects of Palm Oil Empty Fruited Bunch (POEFB) fibre on the drying shrinkage behaviour and compressive strength of foamed concrete (FC) under two different curing conditions. The adopted curing conditions were air curing and tropical natural weather curing. Two volume fractions of POEFB fibre were used, which were $0.25 \%$ and $0.50 \%$ based on dry mix weight with 1 $2 \mathrm{~cm}$ in length. The dimensional stability of the control specimen and POEFB fibre reinforced FCs was obtained by cumulating the measured linear shrinkage or expansion due to different curing conditions. The results from the two different specimens were compared. The results showed that specimens reinforced with POEFB fibre and cured under tropical natural weather condition attained lesser variations of dimensional stability and higher 90-day strength performance index than the reference mix without POEFB fibre. This improvement was attributed to the ability of POEFB fibre to bridge the cement matrix, and irregular wetting process under tropical natural weather curing condition had enabled more production of Calcium Silicate Hydrate gels that gradually blocked the penetration of water into the specimens and increased the compressive strength. It is observed that $11.43 \%$ and $4.46 \%$ of improvement in 90 -day strength performance index were obtained in natural weather cured $0.5 \%$ of POEFB fibre reinforced specimen, with corresponded to the reference mix and $0.25 \%$ of POEFB fibre reinforced specimens, respectively.
\end{abstract}

\section{Introduction}

It is commonly known that foamed concrete $(\mathrm{FC})$ has the advantages of giving lighter dead load, higher thermal insulation characteristic and better acoustical properties than those normal weight concrete. However, FC possesses some weakness that limit it being extensively use in building, such as limited compressive, flexural and tensile strengths, and great dimensional instability, while maintaining its lightness. Several researchers [1-8] have successfully provided a viable solution by adding fibres as the reinforcing agent to enhance the mechanical properties and dimensional stability of lightweight concrete. Among the

\footnotetext{
* Corresponding author: sklim@utar.edu.my
} 
type of fibres, metallic and synthetic fibres are being commonly used in their research. According to Brandt [9], opening and propagation of micro-cracks in a concrete can be effectively controlled by introducing short dispersed fibres in cement matrix. Whilst, long fibres $(50-80 \mathrm{~mm})$ are much able to control larger cracks and therefore contribute to higher final strength. However, the optimum quantity of fibres has to be investigated prior adding into cement matrix. The reasons are high volume of fibre content easily leads to conglomeration of fibre during the composite mixing, while too little fibre content is unable to provide sufficient reinforcing mechanism in cement matrix.

Instead of using metallic and synthetic fibres in lightweight concrete, some researchers have used natural fibres as alternative fibres in lightweight concrete [10-13]. These natural fibres include date palm, equisetum, coconut and jute fibres. Their use, as a construction material, in improving the properties of the composites, does not increase much of the overall composite cost. Besides, the flexibility of POEFB makes it easier to be mixed with cement matrix compared with using harder steel fibre in cement matrix [11]. However, the reinforcing effects from natural fibre in lightweight concrete are varied due to different characteristic among the natural fibres.

Currently, Malaysia is one of the largest palm oil producers in the world, and it contributes about $57.6 \%$ of the total supply of palm oil in the world. According to Roslan et al. [14], Malaysian palm oil industry produces approximately 19 million tonnes (wet weight basis) of Oil Palm Empty Fruit Bunch (OPEFB) in year 2010. Approximately 65\% of OPEFB is incinerated and the bunch ash is recycled back as fertilizer [15]. Therefore, it will be more sustainable and environmental friendly if the fibre extracted from OPEFB, can be further explored and used as construction material. Although some studies and researches on POEFB fibre reinforced concrete have been reported, but the range of the studies and researches in POEFB fibre reinforced FC is extremely limited. For that reason, this research was initiated and focuses on the compressive strength and dimensional stability of FC incorporated with different content of POEFB fibre.

\section{Experimental work}

\subsection{Materials}

Ordinary Portland cement (OPC), quarry sand, water, synthetic foaming agent and POEFB fibre were used to prepare FCs. The OPC used in this experiment is produced by YTL Sdn. Bhd and it complied with the Type I Portland cement as per in ASTM C150 (2007) [16]. Quarry sand which was passed through $600 \mu \mathrm{m}$ of sieve analysis, was used as fine aggregates in this study. The sand was oven-dried at $105^{\circ} \mathrm{C}$ for 24 hours before sieving in order to avoid inconsistency of its moisture content. Normal tap water and locally available synthetic foaming agent were used for production of the FCs in this study. POEFB fibre was torn and cut into $1-2 \mathrm{~cm}$ length. The fibre was oven dried at $105^{\circ} \mathrm{C}$ for an hour to eliminate any moisture content which contributed to its mass and engineering property. Mechanical Properties of POEFB fibre are shows in Table 1. 
Table 1. Mechanical Properties of Palm Oil Fibers.

\begin{tabular}{|c|c|c|c|c|c|c|c|}
\hline Sample & $\begin{array}{c}\text { Diameter, } \\
\text { D (mm) }\end{array}$ & $\begin{array}{c}\text { Area, } \\
\text { A } \\
\left(\mathrm{mm}^{2}\right)\end{array}$ & $\begin{array}{c}\text { Maximum } \\
\text { Load (N) }\end{array}$ & $\begin{array}{c}\text { Original } \\
\text { length } \\
(\mathrm{mm})\end{array}$ & $\begin{array}{c}\text { Elongates } \\
(\mathrm{mm})\end{array}$ & $\begin{array}{c}\text { Tensile } \\
\text { Stress } \\
(\mathrm{MPa})\end{array}$ & $\begin{array}{c}\text { Tensile } \\
\text { Strain }\end{array}$ \\
\hline 1 & 0.300 & 0.071 & 6.791 & 50.000 & 4.650 & 96.071 & 0.093 \\
\hline 2 & 0.300 & 0.071 & 9.655 & 53.000 & 7.632 & 136.596 & 0.144 \\
\hline 3 & 0.400 & 0.126 & 11.360 & 48.000 & 7.728 & 90.401 & 0.161 \\
\hline 4 & 0.330 & 0.086 & 12.292 & 56.000 & 9.072 & 143.718 & 0.162 \\
\hline 5 & 0.250 & 0.049 & 7.727 & 52.000 & 4.316 & 157.415 & 0.083 \\
\hline 6 & 0.220 & 0.038 & 5.181 & 46.000 & 7.222 & 136.288 & 0.157 \\
\hline 7 & 0.320 & 0.080 & 11.057 & 47.000 & 9.870 & 137.477 & 0.210 \\
\hline 8 & 0.270 & 0.057 & 6.736 & 47.000 & 4.982 & 117.649 & 0.106 \\
\hline 9 & 0.310 & 0.075 & 10.107 & 46.000 & 4.738 & 133.905 & 0.103 \\
\hline 10 & 0.270 & 0.057 & 12.202 & 43.000 & 5.590 & 213.117 & 0.130 \\
\hline 11 & 0.380 & 0.113 & 14.548 & 48.000 & 7.440 & 128.272 & 0.155 \\
\hline 12 & 0.270 & 0.057 & 10.984 & 46.000 & 9.292 & 191.838 & 0.202 \\
\hline 13 & 0.370 & 0.108 & 16.625 & 47.000 & 9.447 & 154.616 & 0.201 \\
\hline 14 & 0.320 & 0.080 & 10.053 & 49.000 & 6.762 & 125.002 & 0.138 \\
\hline 15 & 0.300 & 0.071 & 15.285 & 50.000 & 8.900 & 216.242 & 0.178 \\
\hline 16 & 0.360 & 0.102 & 11.843 & 51.000 & 8.262 & 116.353 & 0.162 \\
\hline Mean & $\mathbf{0 . 3 1 1}$ & $\mathbf{0 . 0 7 8}$ & $\mathbf{1 0 . 7 7 8}$ & $\mathbf{4 8 . 6 8 8}$ & $\mathbf{7 . 2 4 4}$ & $\mathbf{1 4 3 . 4 3 5}$ & $\mathbf{0 . 1 4 9}$ \\
\hline Standard & 0.049 & 0.024 & 3.159 & 3.219 & 1.882 & 36.577 & 0.039 \\
\hline Deviation & & & & & & & \\
\hline
\end{tabular}

\subsection{Mix proportions and preparation}

The details of the mixtures for this experiment are tabulated in Table 2. Series 1 was a laboratory trial mix, where a total number of thirteen mixes were prepared using watercement ratio ranging from 0.54 to 0.60 , with 0.02 incremental intervals. POEFB fibre was not added for control mix specimens. However, $0.25 \%$ and $0.50 \%$ of POEFB fibre were added into PF25 and PF50 mixes respectively, in order to study its effect on 28-day FC compressive strength under water curing condition. The mixes with optimum strength to $1000 \mathrm{~kg} / \mathrm{m}^{3}$ density ratio [17] were selected for further investigation in Series 2. Series 2 focuses on the dimensional stability and 90-day compressive strength of the FC specimens as a result of two different curing conditions (air curing and tropical natural weather curing). Before exposing to different types of curing, all specimens in Series 2 had undergone the first 7 days initial water curing. Subsequently, the curing was continued with either air curing or tropical natural weather curing, for the remaining days until Day- 90 . Water curing was done with the temperature in the range of $25-28^{\circ} \mathrm{C}$. For air curing, the specimens were placed in the laboratory at ambient room temperature $\left(29-32^{\circ} \mathrm{C}\right)$ with $65 \%$ of average relative humidity. For tropical natural weather curing, the specimens were cured under Malaysian tropical climate. The temperature ranges $29-35^{\circ} \mathrm{C}$ and with $50-90 \%$ of relative humidity. 
Table 2. Mix proportions of various type of FC.

\begin{tabular}{|c|c|c|c|c|c|c|}
\hline \multirow{2}{*}{ Specimen } & \multirow{2}{*}{$\begin{array}{l}\mathrm{w} / \mathrm{c} \\
\text { ratio }\end{array}$} & \multicolumn{5}{|c|}{ Materials $\left[\mathrm{kg} / \mathrm{m}^{3}\right]$} \\
\hline & & Cement & Sand & Water & Foam & POEFB fibre \\
\hline $\mathrm{Ctrl}^{1}-54^{3}$ & 0.54 & 500 & 500 & 270 & 20.44 & 0 \\
\hline Ctrl-56 & 0.56 & 500 & 500 & 280 & 19.56 & 0 \\
\hline Ctrl-58 & 0.58 & 500 & 500 & 290 & 18.66 & 0 \\
\hline Ctrl-60 & 0.60 & 500 & 500 & 300 & 18.66 & 0 \\
\hline Ctrl-62 & 0.62 & 500 & 500 & 310 & 16.89 & 0 \\
\hline $\mathrm{PF} 25^{2}-54$ & 0.54 & 500 & 500 & 270 & 20.44 & 2.5 \\
\hline PF25-56 & 0.56 & 500 & 500 & 280 & 20.00 & 2.5 \\
\hline PF25-58 & 0.58 & 500 & 500 & 290 & 16.89 & 2.5 \\
\hline PF25-60 & 0.60 & 500 & 500 & 300 & 13.33 & 2.5 \\
\hline PF50 ${ }^{2}-54$ & 0.54 & 500 & 500 & 270 & 26.22 & 5.0 \\
\hline PF50-56 & 0.56 & 500 & 500 & 280 & 24.89 & 5.0 \\
\hline PF50-58 & 0.58 & 500 & 500 & 290 & 24.89 & 5.0 \\
\hline PF50-60 & 0.60 & 500 & 500 & 300 & 24.00 & 5.0 \\
\hline $\begin{array}{l}\text { Note: } \\
{ }^{1} \mathrm{Ctrl}=\text { contr } \\
{ }^{2} \mathrm{PF} 25 \text { or PF } \\
\text { into the FC n } \\
{ }^{3} \text { The last two }\end{array}$ & $\begin{array}{l}\text { ix of } \\
0.25 \\
\text { ure }\end{array}$ & or lab & $y$ tr & 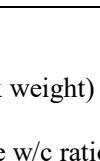 & POEFI & 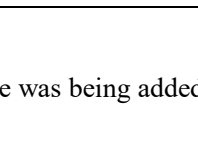 \\
\hline
\end{tabular}

For all the specimens, cement to sand ratio was fixed at unity (by weight) and the foaming agent was diluted with water in a ratio of 1: 30 (by volume). The designated density of FCs in this study was fixed at $1300 \pm 50 \mathrm{~kg} / \mathrm{m}^{3}$. Therefore, a required amount of stable foam, produced by dry prefoamed method [18], was added into the slurry cement mortar mix in order to obtain the required density. $100 \mathrm{~mm} \times 100 \mathrm{~mm} \times 100 \mathrm{~mm}$ cubic mould and $100 \mathrm{~mm} \times 200 \mathrm{~mm} \times 400 \mathrm{~mm}$ prismatic mould were used to produce specimens for compression test and dimensional stability test. All specimens were demoulded 24 hours after casting.

\subsection{Testing methods}

Before casting, the fresh cement mortar and foamed concrete were tested for their flowability and consistency using flow table spread test and inverted slump test in accordance to ASTM C1437 (2007) [19] and ASTM C1611 (2007) [20], respectively. The diameters for four angles of the spread concrete were measured and the average reading was recorded. Compression test was conducted by using Instron 5582 Testing Machine in accordance with BS EN 12390-3 (2002) [21]. Dimensional stability was performed by measuring linear shrinkage and expansion of concrete block according to RILEM CPC9 (1994) [22]. Four strain measuring discs were affixed to the concrete surface $(400 \mathrm{~mm} \times$ $200 \mathrm{~mm})$, two discs were affixed parallel to concrete specimen vertical side $(100 \mathrm{~mm} \times 200$ $\mathrm{mm})$ and the other two were affixed parallel to the horizontal side $(100 \mathrm{~mm} \times 400 \mathrm{~mm})$, using epoxy adhesive. Strain gauge meter was used to measure dimension changes of the specimens from the very first day of air curing or tropical natural weather curing until 90 days of age. These cumulative dimensional changes exhibited in this experiment show trends of contraction/expansion corresponding to variation of surrounding condition and 
temperature. The degree of deformation for the specimen can be calculated using Equation (1).

$$
\Delta=\varepsilon \times \mathrm{L}
$$

Where, $\Delta$ is deformation, $\varepsilon$ is strain or equals to measured scale, $\delta \times$ strain factor $(1.587$ $\left.10^{-5}\right), \mathrm{L}$ is original length of specific surface [mm].

\section{Results and discussion}

\subsection{Series 1 (laboratory trials)}

Table 3 tabulated the results of average inverted slump cone spread values, stability, consistency, 28-day compressive strength and strength to $1000 \mathrm{~kg} / \mathrm{m}^{3}$ density ratio (performance index). Referring to the inverted slump cone spread values in Table 3, the fluidity of FCs is significantly affected by the w/c ratio and percentage of POEFB fibre being added into the mixture. Higher $\mathrm{w} / \mathrm{c}$ ratio increases the inverted slump cone spread values in each category of the trial mix. Whereas, incorporating higher content of palm oil fibre decreases the inverted slump spread value. This is due to the hydrophilic nature of the dried palm oil fibre, which absorbed portion of the water content required for cement hydration [12]. Since the required amount of water was not made available for cement hydration, therefore overall fluidity for PF50 and PF25 is lower than that of control mix.

Table 3. Summary of Series 1 (initial laboratory trials).

\begin{tabular}{|c|c|c|c|c|c|}
\hline Specimen & $\begin{array}{c}\text { Inverted slump } \\
\text { cone spread value } \\
{[\mathrm{mm}]^{\mathrm{a}}}\end{array}$ & Stability $^{\mathrm{b}}$ & Consistency ${ }^{\mathrm{c}}$ & $\begin{array}{c}\text { 28-day } \\
\text { Compressive } \\
\text { Strength }[\mathrm{MPa}]^{\mathrm{d}}\end{array}$ & $\begin{array}{l}\text { Strength } \\
\text { performance } \\
\text { Index }^{\mathrm{e}}\end{array}$ \\
\hline Ctrl-54 & 545 & 0.97 & 1.01 & 5.29 & 4.06 \\
\hline Ctrl-56 & 584 & 0.95 & 1.08 & 5.80 & 4.47 \\
\hline Ctrl-58 & 654 & 0.97 & 1.05 & 5.53 & 4.16 \\
\hline Ctrl-60 & 681 & 1.00 & 1.02 & 5.41 & 4.12 \\
\hline Ctrl-62 & 684 & 0.96 & 1.05 & 5.38 & 4.11 \\
\hline PF25-54 & 513 & 0.96 & 1.01 & 5.00 & 3.96 \\
\hline PF25-56 & 539 & 0.96 & 1.05 & 5.77 & 4.43 \\
\hline PF25-58 & 639 & 0.96 & 1.06 & 5.51 & 4.21 \\
\hline PF25-60 & 667 & 0.95 & 1.05 & 5.33 & 4.12 \\
\hline PF50-54 & 503 & 0.95 & 1.02 & 5.30 & 4.23 \\
\hline PF50-56 & 533 & 0.94 & 1.08 & 5.69 & 4.34 \\
\hline PF50-58 & 673 & 0.93 & 1.05 & 6.37 & 5.00 \\
\hline PF50-60 & 673 & 0.98 & 1.02 & 6.29 & 4.88 \\
\hline
\end{tabular}

\footnotetext{
Note:
${ }^{a}$ Inverted slump cone spread values were obtained by averaging the spread diameter of four different angles.

${ }^{\mathrm{b}}$ Stability $=$ proportion of measured fresh density to measured hardened density.

${ }^{\mathrm{c}}$ Consistency $=$ proportion of measured fresh density to designated density, which is fixed at $1300 \mathrm{~kg} / \mathrm{m}^{3}$.

d28-day strength was obtained by averaging the crush value of three specimens.

${ }^{\text {e}}$ Strength performance index = proportion of 28-day compressive strength [MPa] to its hardened bulk density

The mixes highlighted in bolded font were chosen due to their best strength to $1000 \mathrm{~kg} / \mathrm{m}^{3}$ density ratio.
} 
Referring to Table 3, the best performance ratio for the Ctrl, PF25 and PF50 specimens were obtained at $0.56,0.56$ and 0.58 of $\mathrm{w} / \mathrm{c}$ ratios, respectively. Theoretically, as the density of the concrete increases, its compressive strength would increases correspondingly. However, the hardened densities among the FC specimens are slightly different, although the targeted density was within $1300 \pm 50 \mathrm{~kg} / \mathrm{m}^{3}$. Therefore, mixes that have optimum strength to density ratio without compromising their stability and consistency were selected for further investigation [17].

\subsection{Series 2}

In Series 2, further investigation was concentrated on the dimensional stability, and 90-day compressive strength of the specimen with the highest strength performance index obtained in Series 1, namely Ctrl-0.56, PF25-0.56 and PF50-0.58. All the tests for FC were done in triplicate, but only the average values were reported.

\subsubsection{Dimensional stability}

The results of dimensional stability of POEFB fibre reinforced FCs that cured under air curing and tropical natural weather curing condition are shown in Figures 1 and 2, respectively. For air curing condition, the specimens shrunk with a decreasing rate with advancing age. This is due to the loss of water in concrete via evaporation, leading to specimens' shrinkage at early age. Subsequently, less water was available at the later age due to discontinuous water supply for specimens cured under air curing condition. Therefore, the shrinkage of air cured specimens increased gradually.

On the other hand, for specimens cured under natural weather condition, the dimensional stability was varying depending on outdoor humidity. Rain water was absorbed into the FC specimens through capillary pores during rainy season and it caused the specimen to expand. Conversely, internal water evaporated when the specimens exposed to hot scorching sun caused the specimens to shrink. This irregular wetting process during rainy days under tropical natural weather curing condition allowed continuity of hydration reaction in specimens and produced more Calcium Silicate Hydrate gels that gradually blocked the penetration of water into the specimens. As a result, tropical natural weather cured specimens had lesser volume changes at the later age, compared with air cured specimens, as shown in Figure 2. In addition, it was found that specimens incorporated with POEFB fibre encountered lesser dimensional changes than the control mix for both curing conditions. This result indicated that POEFB fibre has the bridging ability inside the cement matrix, reduced capillary pores, and therefore reduced the dimensional changes of the specimens. 


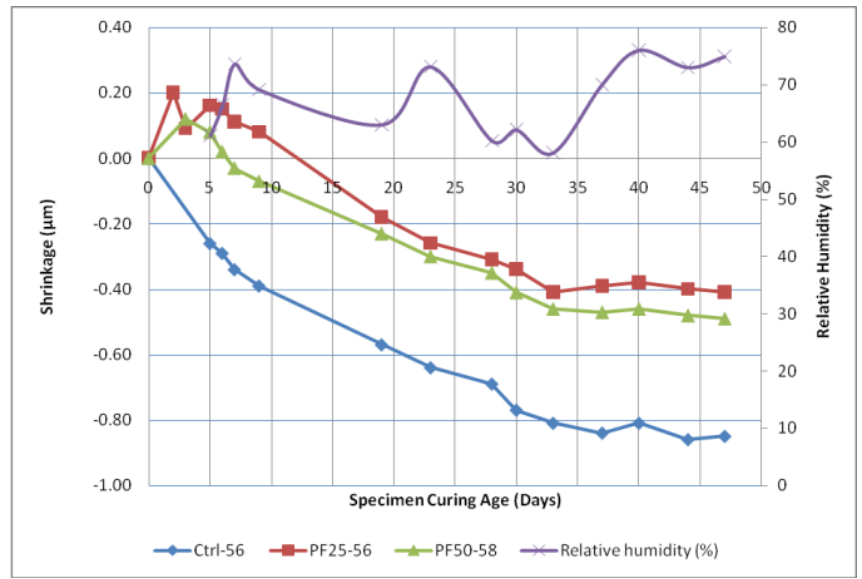

Fig. 1. Dimensional stability of POEFB fibre reinforced FC under air curing conditions.

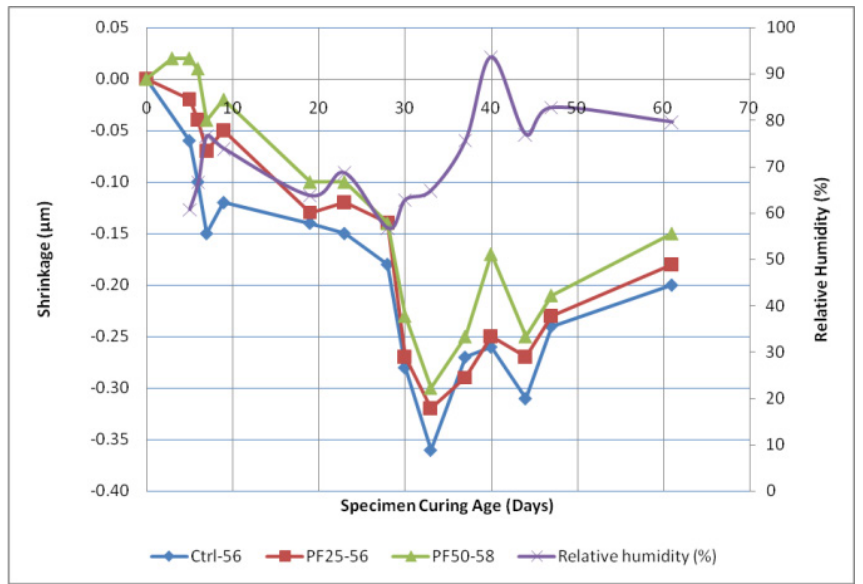

Fig. 2. Dimensional stability of POEFB fibre reinforced FC under tropical natural weather curing conditions.

\subsubsection{Compressive strength}

The compressive strength and strength performance index for Ctrl-56, PF25-56 and PF5058, are shown in Figures 3 and 4, respectively. Table 4 shows the comparison of strength performance index among the FCs with and without POEFB fibre, in both air curing and tropical natural weather curing conditions. Based on the results, specimens with POEFB fibre obtained higher 90-day compressive strength than that of reference specimen, regardless of the type of curing condition being adopted. This is due to fibre inside the FC was functioned as reinforcing agent to bridge the cement matrix firmly than plain concrete [12].

It was found that tropical natural weather cured specimens achieved higher compressive strength and strength performance index than those of air cured specimens, regardless of the presence of POEFB fibre in the specimens. This could be due to the presence of water under tropical natural weather condition enables continuity of the hydration process and the production of more Calcium Silicate Hydrate gels, which reduced the porosity in hydrated 
cement paste. These findings are supported by the results shown in Figure 3, Figure 4, and Table 4.

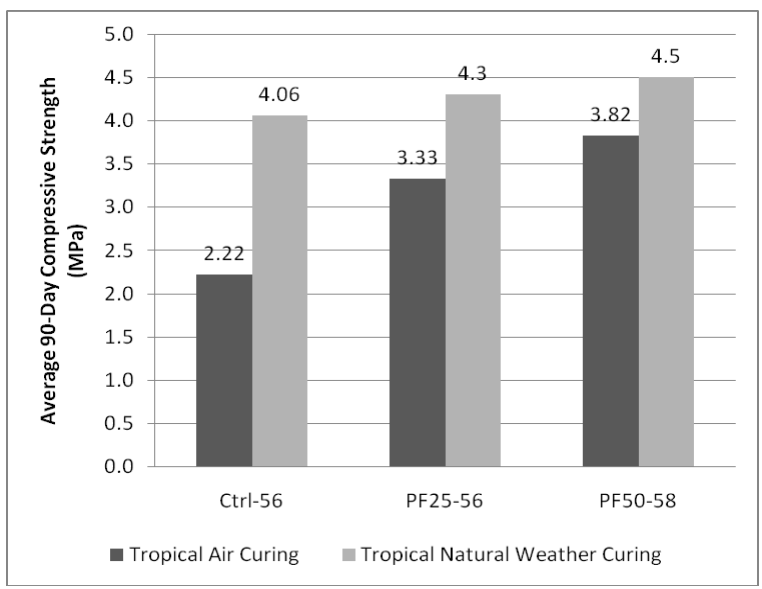

Fig. 3. Average 90-day compressive strength Ctrl-56, PF25-56 and PF50-58 under two different curing conditions.

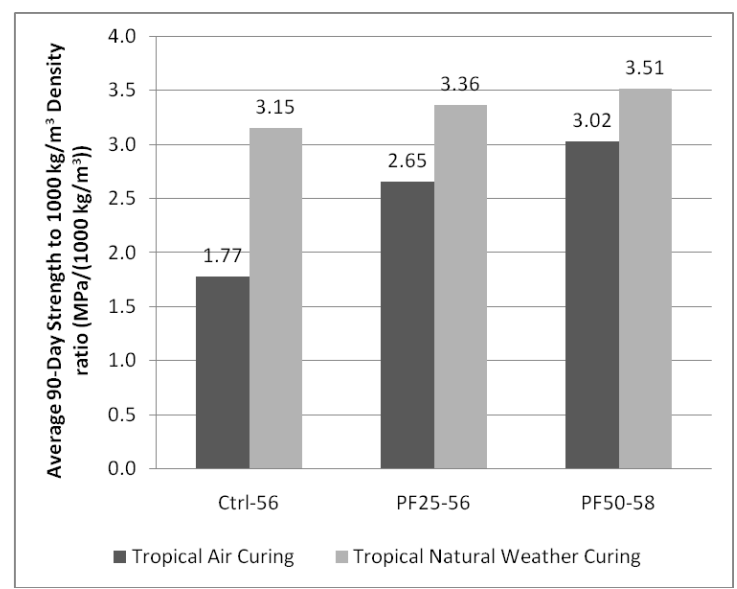

Fig. 4. Average 90-day strength performance index for Ctrl-56, PF25-56 and PF50-58 under two different curing conditions.

Table 4. Relationship of 90-day strength performance index and fibre content.

\begin{tabular}{ccccccc}
\hline \multirow{2}{*}{$\begin{array}{c}\text { Curing } \\
\text { Condition }\end{array}$} & \multicolumn{2}{c}{$\begin{array}{c}\text { 90-day Strength Performance } \\
\text { Index [MPa/ 1000kgm }\end{array}$} & & PF25-56 & PF50-58 & PF50-58 \\
\cline { 2 - 7 } & Ctrl-56 & PF25-56 & PF50-58 & Ctrl-56 & Ctrl-56 & PF25-56 \\
\hline Air & 1.77 & 2.65 & 3.02 & $49.72 \%$ & $70.62 \%$ & $13.96 \%$ \\
\hline $\begin{array}{c}\text { Tropical natural } \\
\text { weather }\end{array}$ & 3.15 & 3.36 & 3.51 & $6.67 \%$ & $11.43 \%$ & $4.46 \%$ \\
\hline
\end{tabular}




\section{Conclusions}

Based on these experimental investigations, some conclusions were drawn and are listed as below:

(a) Foamed concrete (FC) reinforced with $0.50 \%$ of Palm Oil Empty Fruit Bunch (OPEFB) fibre (1-2 cm in length) shows better enhancement in compressive strength and dimensional stability under tropical air curing, compared to reference mix without POEFB fibre and $0.25 \%$ POEFB fibre reinforced FC.

(b) The inclusion of dried POEFB fibre inside FC requires higher water content in order to achieve a consistent mix compared with that of reference mix with higher water content.

(c) Tropical natural weather cured POEFB fibre reinforced FCs achieved higher compressive strength than those of air cured POEFB fibre reinforced FCs. This could be due to the presence of water under tropical natural weather condition enables continuity of the hydration process and the production of more Calcium Silicate Hydrate gels, which reduced the porosity in hydrated cement paste.

Effort and contribution by Ms Hew Yi Wen and Mr Li Siew Wu on these experimental investigations are highly appreciated.

\section{References}

1. A. D. Oğuz, G. Rüstem, C. A. Abdulkadir, Effects of steel fibres on the mechanical properties of natural lightweight aggregate concrete, Materials Letters, 59(27), 33573363 (2005)

2. B. Chen, J. Liu, Contribution of hybrid fibres on the properties of the high-strength lightweight concrete having good workability, Cement and Concrete Research, 35(5), 913-917 (2005)

3. A. Sivakumar, M. Santhanam, Mechanical properties of high strength concrete reinforced with metallic and non-metallic fibres, Cement and Concrete Composites, 29(8), 603-608 (2007)

4. B. Chen, Z. Wu, N. Liu, Experimental Research on Properties of High-Strength Foamed Concrete, J. of Materials in Civil Engineering, 24(1), 113-118 (2012)

5. K. Aghaee, M.A. Yazdi, K.D. Tsavdaridis, Mechanical properties of structural lightweight concrete reinforced with waste steel wires. Magazine of Concrete Research, 66(1). 1 - 9 (2014)

6. R. Yu, D. van Onna, P. Spiesz, Q. Yu, H. Brouwers, Development of ultra-lightweight fibre reinforced concrete applying expanded waste glass, J. Cleaner Production, 112, 690-701 (2016)

7. H. Hardjasaputra, G. Ng, G. Urgessa, G. Lesmana, S. Sidharta1, Performance of lightweight natural-fiber reinforced concrete, MATEC Web of Conferences, 138, 01009 (2017)

8. J. Li, J. Niu, C. Wan, X. Liu, Z. Jin, Comparison of flexural property between high performance polypropylene fiber reinforced lightweight aggregate concrete and steel fiber reinforced lightweight aggregate concrete. Construction and Building Materials, 157, 729-736 (2017)

9. A. M. Brandt, Fibre reinforced cement-based (FRC) composites after over 40 years of development in building and civil engineering, Composites Structures, 86(1-3), 3-9 (2008) 
10. A. Kriker, G. Debicki, A. Bali, M. M. Khenfer, M. Chabannet, Mechanical properties of date palm fibres and concrete reinforced with date palm fibres in hot-dry climate, Cement and Concrete Composites, 27(5), 554-564 (2005)

11. A. Majid, L. Anthony, S. Hou, C. Nawawi, Mechanical and dynamic properties of coconut fibre reinforced concrete, Construction and Building Materials, 30, 814-825 (2012)

12. C. Sumit, P. K. Sarada, R. Aparna, K. B. Ratan, A. Basudam, S.B. Majumder, Improvement of the mechanical properties of jute fibre reinforced cement mortar: A statistical approach, Construction and Building Materials, 38, 776-784 (2013)

13. N. Zahra, F. Mehdi, E. Ghanbar, H. Yahya, Manufacture of lignocellulosic fibrecement boards containing foaming agent, Construction and Building Materials, 35, 408-413 (2012)

14. A. Roslan, F. K. Mohammad, A. N. A. Borhan, S. M. Arif, A study on the Malaysian Oil Palm Biomass Sector - Supply and Perception of Palm Oil Millers, Oil Palm Industry Economic J., 11(1), 28-41 (2011)

15. M. S. Rosnah, W. H. Wan Hasamudin, M. T. Ab Gapor, H. Kamarudin, Thermal properties of oil palm fibre, cellulose and its derivatives, J. of Oil Palm Research, 18, 272-277 (2006)

16. America Society of Testing and Materials, ASTM C 150-05: Standard Specification for Portland Cement, ASTM International, Conshohocken, Pennsylvania, United States (2007)

17. H. Kurama, I. B. Topcu, C. Karakurt, Properties of the autoclaved aerated concrete produced from coal bottom ash, J. of Materials Processing Technology, 209(2), 767773 (2009)

18. K. Ramamurthy, E. K. K. Nambiar, G. I. S. Ranjani, A classification of studies on properties of foam concrete, J. of Cement and Concrete Composites, 31, 388-396 (2009)

19. America Society of Testing and Materials, ASTM C1437: Standard Test Method for Flow of Hydraulic Cement Mortar, ASTM International, Conshohocken, Pennsylvania, United States (2007)

20. America Society of Testing and Materials, ASTM C1611: Standard Test Method for Slump Flow of Self Consolidating Concrete, ASTM International, Conshohocken, Pennsylvania, United States (2007)

21. British Standard Institute, BS EN 12390-3: Testing hardened concrete - Part 3: Compressive strength of test specimens, BSI, London (2002)

22. RILEM CPC9, Technical recommendations for the testing and use of construction materials: Measurement of shrinkage and swelling of concrete, 1975, E\& FN SPON, London (1994) 